\title{
Antidiabetic Activity of Azadirachta excelsa Extract on Alloxan Induced Diabetic Rats
}

\author{
Nurdiana S*, Mohamad Shukri, K., Elizabeth Jega J. and Nurul 'Izzati, S \\ Faculty of Applied Sciences, Universiti Teknologi MARA, 40450 Shah Alam, Selangor, Malaysia
}

\begin{abstract}
Plant-based remedies have been used to treat numerous diseases for thousands of years in various parts of the world. Azadirachta excelsa or sentang traditionally used by Malay as an agent for lowering blood glucose. The study was designed to evaluate the antidiabetic properties of this plant by measuring the plasma blood glucose level, the percentage of HbA1c and the plasma insulin level. Thirty two Sprague dawley rats were divided into four groups which received different treatments. The first and second groups served as positive and negative control were treated with saline respectively while the rats in the third group were received metformin. The fourth group was treated with ethanolic extract of $A$. excelsa. After 14 days of treatment, the plant extract was significantly reduced the fasting blood glucose and the concentration of $\mathrm{HbA1} \mathrm{c}$ in diabetic rats by $72.89 \%$ and $6.58 \%$ respectively. The plasma insulin in diabetic rats was also significantly increased after treated with plant extract. These results suggest that the ethanolic extract of $A$. excelsa possess antidiabetic activity by improving the insulin secretion, with consequent decrease in the level of plasma blood glucose and $\mathrm{HbA1c}$.
\end{abstract}

Keywords: Azadirachta excelsa, blood glucose, $\mathrm{HbA1c}$, insulin.

\section{INTRODUCTION}

Diabetes mellitus is a heterogeneous metabolic disorder that has affected substantial population regardless of sex, age and socio economic status [1]. According to World Health Organization, the number of diabetes cases in Southern Asia and Western Pacific currently at 171 million and it was expected to reach 336 million by the end of 2030 [2]. Specific diabetic risk factor such as glycation of protein including haemoglobin and coagulation abnormalities, and subsequent endothelial dysfunction, may also contribute to cardiovascular complications. Glycosylated peptides are elevated several folds in diabetics. The use of the glycosylated hemoglobin (HbAlc) assay for long-term diabetic monitoring of diabetic control is gaining much wider use and acceptance [3].

There were many reviews on plants remedies that possess experimental and clinical antidiabetic activity [4]. In Malaysia, medicinal plants are used according to the folk traditions of natives or people who came from India, China or Arab countries. Such plants are used in formulations of home remedies such as teas, decoctions or tinctures. Azadirachta excelsa, a typical wild plant found in Malaysia. Azadirachta is a genus from two species of trees in the flowering plant of family Meliaceae. To our best knowledge, the antidiabetic activity of this plant has not been investigated scientifically. However, previous work was reported that the chloroform extracts of A. excelsa stem demonstrated anticancer activity [5]. Young shoots can be

*Address correspondence to this author at the Faculty of Applied Sciences, Universiti Teknologi MARA, 40450 Shah Alam, Selangor, Malaysia; Tel: +603-55437857;

E-mail: nurdiana7251@salam.utim.edu.my eaten in salad and are believed to be good for lowering blood pressure.

\section{MATERIALS AND METHODS}

\section{Preparation of Azadirachta excelsa Leaves Extract}

The powdered leaves of $A$. excels $a$ were soaked in $70 \%$ ethanol for two days at room temperature $\left(37^{\circ} \mathrm{C}\right)$. The suspension was then filtered to obtain the extract. The extract was then evaporated using the rotary evaporator at $40^{\circ} \mathrm{C}$ until it was completely dried [6]. A dark semi-solid material was obtained and stored at $4^{\circ} \mathrm{C}$ to be used later on.

\section{Induction of Diabetes}

Rats weighing between 160 to $300 \mathrm{~g}$ were fasted overnight and injected by intraperitonial administration of freshly prepared alloxan monohydrate $(130 \mathrm{mg} / \mathrm{kg})$ in saline solution of $\mathrm{pH}$ 7.4. On day seventh, the rats showing stable glycemic values above $130 \mathrm{mg} / \mathrm{dl}$ or $7.0 \mathrm{mmol} / \mathrm{L}$ were considered diabetic and selected for further experimentation. Blood glucose levels of the rats were estimated by collecting the blood samples from the tail vain by using Glucometer Accu-check Active.

\section{Experimental Design}

The rats were divided into four groups with six rats in each group and treated orally twice a day as follows:

Group A: normal rats received saline.

Group B: diabetic rats received saline.

Group C: diabetic rats received metformin.

Group D: diabetic rats received ethanolic extract of $A$. excels $a$ at dose of $500 \mathrm{mg} / \mathrm{kg}$. 


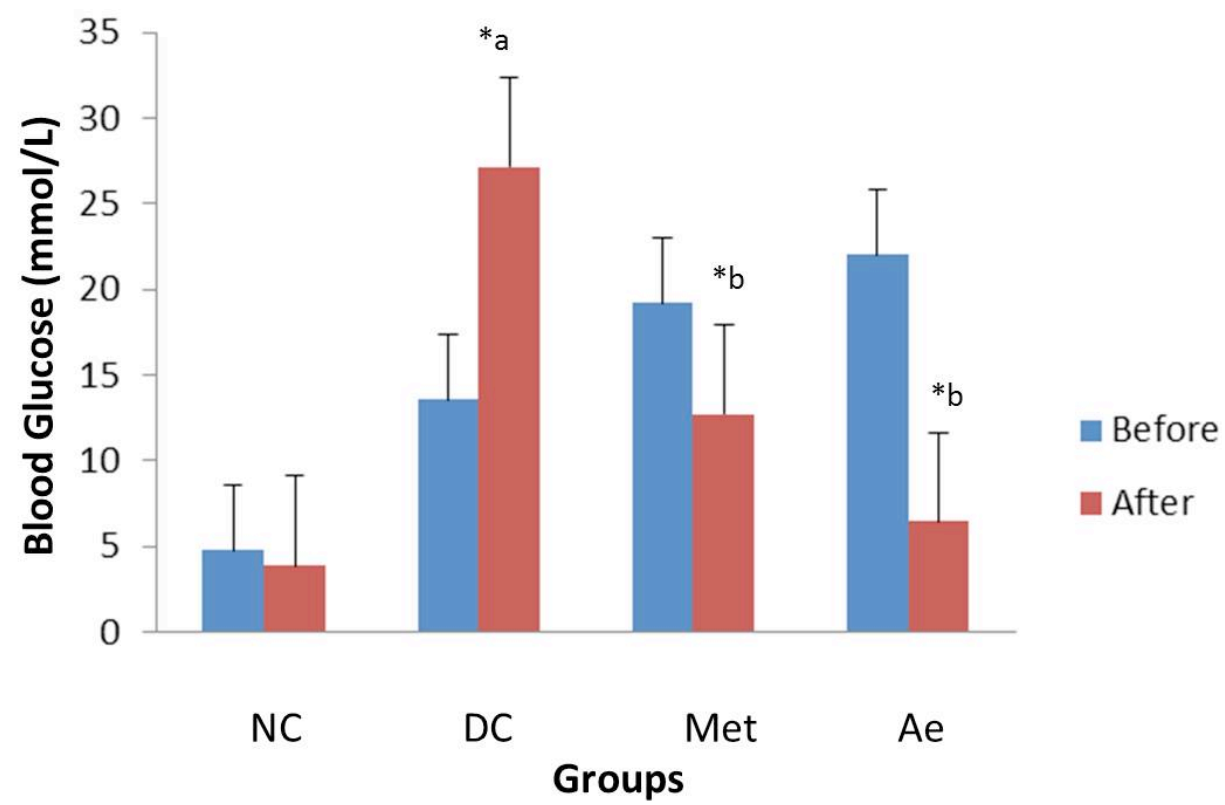

Fig. (1). Plasma blood glucose in experimental rats before and after treatment. Data are expressed as means \pm SEM ( $n=6)$. *a-P $<0.01$ compared with the corresponding value for normal control rats; *b-P $<0.001$ compared with the corresponding value for diabetic control rats. Ae (A.excelsa ethanolic extracts treatment), Met (Metformin treatment), DC (Diabetic control), NC (Normal control).

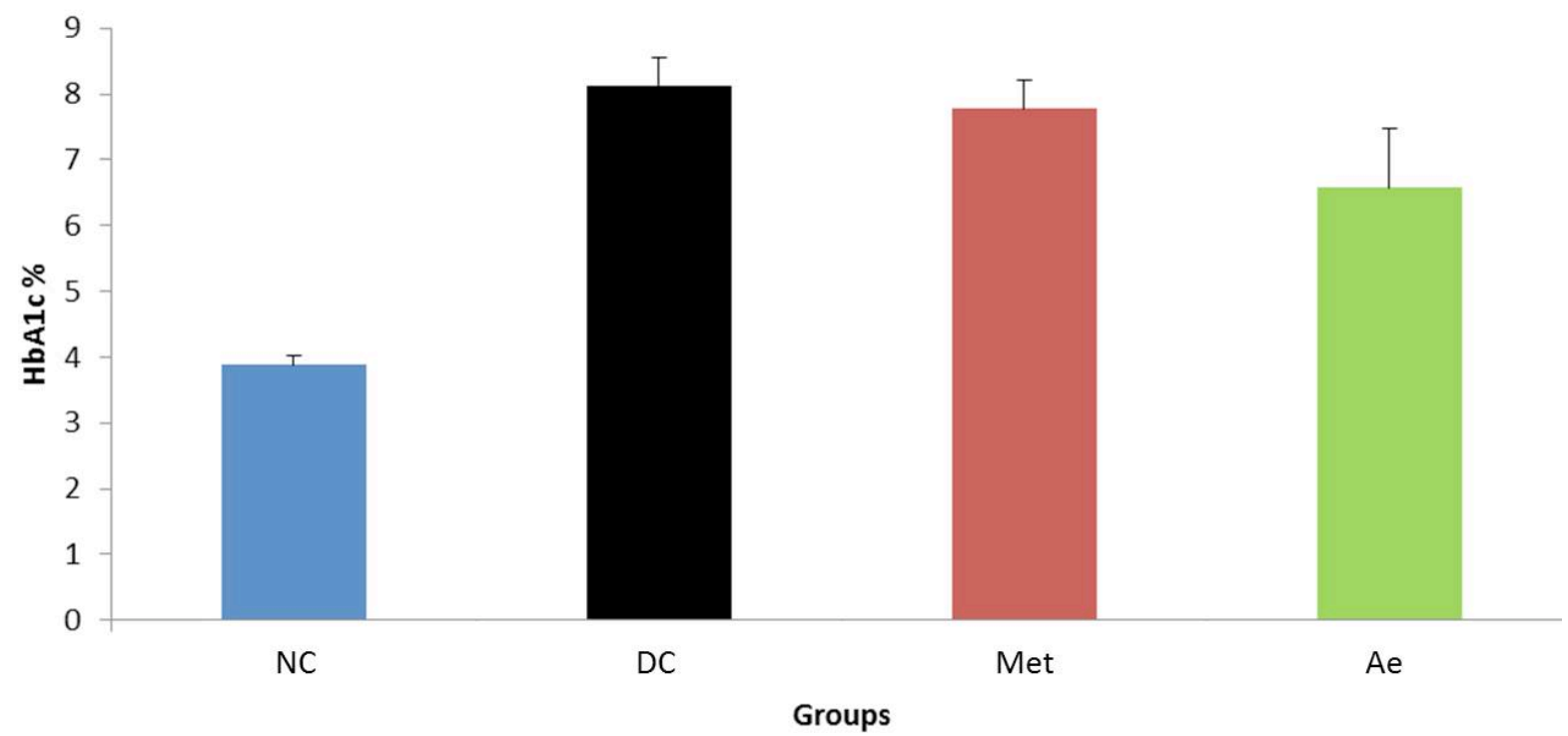

Fig. (2). The percentage of $\mathrm{Hb}_{\mathrm{Alc}}$ within 14 days of treatment. Data were expressed as means $\pm \mathrm{SEM}$; $\mathrm{n}=6$; Ae (A.excelsa ethanolic extracts treatment), Met (Metformin treatment), DC (Diabetic control), NC (Normal control).

On day 15 of treatment, after 8 hours of fast, all animals were scarified by decapitation. Blood were withdrawn for blood glucose, HbAlc and insulin analysis while the uterine were harvested for histological study.

\section{Glycated Haemoglobin Assay}

A $1.5 \mu \mathrm{L}$ of blood sample were collected with the integrated sampling device by touching the surface of the blood drop until it filled the capillary end. Later, the sampling device was inserted into the Affinion Analyser system. The sample was automatically diluted and mixed with a buffer that lyses the erythrocytes and precipitates the haemoglobin. The analyser evaluated the precipitation on the membrane. The ratio between the glycated haemoglobin and the total haemoglobin intensities was proportional to the percentage $\mathrm{Hb}_{\mathrm{Alc}}$ displayed on the Analyzer screen.

\section{RESULTS}

\section{The Plasma Blood Glucose Level}

The effects of $A$. excelsa on blood glucose levels in diabetic rats are given in Fig. (1). The plant extract has produced a significant anti-hyperglycemic activity with $60.7 \%$ reduction in the blood glucose. Treatment of the diabetic rats with metformin $(50 \mathrm{mg} / \mathrm{kg}$ b.w) has resulted in $31.3 \%$ reduction in their blood glucose.

\section{The Percentage of $\mathbf{H b}_{\mathrm{A1c}}$}

As shown in Fig. (2), the highest percentage of total $\mathrm{HbAlc}$ was found in untreated diabetic rat which is $8.13 \%$. However, administration of metformin and ethanolic extracts of $A$. excelsa for two weeks have successfully reduced the 


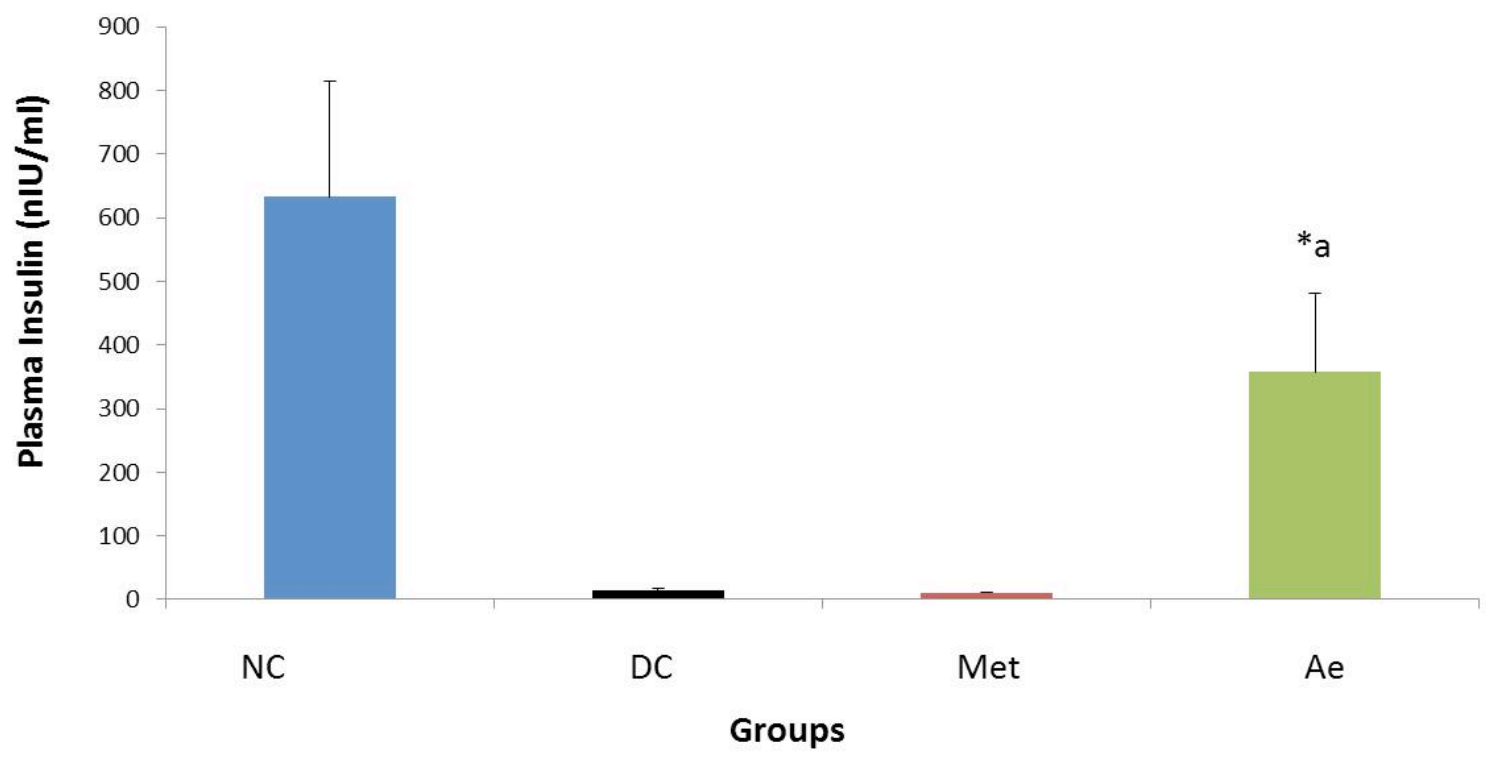

Fig. (3). The concentration of plasma insulin of each group after 14 days of treatment. Data were expressed as means \pm SEM; $n=3$; * statistical significant versus diabetic control $(\mathrm{p}<0.05)$; Ae (A.excelsa ethanolic extracts treatment), Met (Metformin treatment), DC $(\mathrm{Diabetic}$ control), NC (Normal control).

percentage of HbAlc which is $7.78 \%$ and $6.58 \%$ respectively.

\section{Plasma insulin}

As showed in Fig. (3), the secretion of insulin was suppressed effectively by a single intraperitoneal injection of alloxan monohydrate. Administration of A. excelsa leaves extract was significantly increases the plasma insulin level in the diabetic rats. The finding seems to suggest that the plant extracts work as antidiabetic agents via insulinogenic activity. $A$. excelsa might stimulate an immediate insulin secretion from the remnant $\beta$-cells or regenerated $\beta$-cells; as observed in other plant extracts [7]. However, administration of metformin during experimental period obviously failed to modify the insulin level of diabetic rats.

\section{DISCUSSION AND CONCLUSION}

The use of plants for the treatment of patients with diabetes is common throughout the world. In the present study, alloxan-induced diabetic rats exhibit a significant decrease in plasma glucose level when treated with $A$. excelsa leaves extract. Glucose lowering effect of $A$. excelsa might be due to stimulation of surviving $\beta$-cells of islets of Langerhans leading to more insulin release. This was confirmed by the increased levels of plasma insulin in diabetic rats treated with $A$. excelsa. The plant was caused a large increase of plasma insulin in alloxan-treated animals but had no effect on insulin in control rats.

Determining the glycated haemoglobin (HbAlc) serves as an appropriate method for diabetic screening. Greater long term variability in $\mathrm{HbA1c}$ increases the risk of diabetic microangiopathies and macroangiopathies [8]. The risk of cardiovascular disease has been shown to be elevated in patients with types 2 diabetes mellitus with increase fluctuations in HbA1c [9]. Previous work was reported the increment of glycosylation proteins, including $\mathrm{Hb}$ found in uncontrolled or poorly controlled diabetes [10]. Aligned with other work [11], the high levels of Hb1Ac was observed in alloxan-induced diabetic rats together with corresponding increased plasma glucose values. In our study, $\mathrm{HbAlc}$ increased in diabetic animals compared to normal rats. $A$. excelsa and metformin treatments reduced the $\mathrm{HbA} 1 \mathrm{c}$ values to near normal levels due to improved glycemic control.

These findings indicated that $A$. excelsa acts primarily as antidiabetic agent by stimulating the secretion of insulin, consequent with reduction of plasma blood glucose and HbA1c values.

\section{CONFLICT OF INTEREST}

The authors confirm that this article content has no conflicts of interest.

\section{ACKNOWLEDGMENTS}

Declared none.

\section{REFERENCES}

[1] Kannur DM, Hukkeri VI, Akki KS. Antidiabetic activity of Caesalpinia bonducella seed extracts in rats. Fitoterapia 2006; 77(8): 546-9.

[2] Sunil C, Ignacimuthu S, Agastian P. Antidiabetic effect of Symplocos cochinchinensis (Lour.) S. Moore. in type 2 diabetic rats. Journal of Ethnopharmacology 2011; 134(2): 298-304.

[3] Bhandari U, Jain N, Ansari MN, Pillai KK, Beneficial effect of Embelia ribes ethanolic extract on blood pressure and glycosylated hemoglobin in streptozotocin-induced diabetes in rats. Fitoterapia 2008; 79(5): 351.

[4] Shokeen P, Anand P, Murali YK, Tandon V. Antidiabetic activity of $50 \%$ ethanolic extract of Ricinus communis and its purified fractions. Food Chem Toxicol 2008; 46(11): 3458-66.

[5] Cui B, Chai H, Constant HL, et al. Limonoids from Azadirachta excelsa. Phytochemistry 1998; 47(7): 1283-87.

[6] Mustafa MA, Al-Khazraji A. Effect of some plant extracts on the Culex pipiens molestus Forskal larvae. Iraqi J Veterinary Sci 2008; 22 (1): 9- 12.

[7] Eliza J, Daisy P, Ignachimuthu S, Duraipandiyan V. Antidiabetic and antilipidemic effect of eremanthin from Costus speciosus (Koen.)Sm., in STZ-induced diabetic rats. Chemico-Biol Interact 2009; 1(182): 67- 72 . 
[8] Koga M, Murai J, Morita S, Saito H, Kasayama S. Comparison of annual variability in $\mathrm{HbA} 1 \mathrm{c}$ and glycated albumin in patients with type 1 vs. type 2 diabetes mellitus. J Diab Complicat 2013; 2: 1225

[9] Bouchi R, Babazono T, Mugishima, M, Yoshida, N, Nyumura, I, Toya, K. Fluctuations in $\mathrm{HbA1c}$ are associated with a higher incidence of cardiovascular disease in Japanese patients with type 2 diabetes. J Diab Investig 2012; 3: 148-55.
[10] Carlsson J, Gullstrand C, Ludvigsson J, Lundström I, Winquist F. Detection of global glycosylation changes of serum proteins in type 1 diabetes using a lectin panel and multivariate data analysis. Talanta 2008; 76 (2): 333-7.

[11] Adeneye AA, Adeyemi OO. Further evaluation of antihyperglycaemic activity of Hunteria umbellata (K. Schum) Hallier f. seed extract in experimental diabetes. J Ethnopharmacol 2009; 126 (2): 238-43.

Received: May 29, 2013

(C) Nurdiana et al.; Licensee Bentham Open.

This is an open access article licensed under the terms of the Creative Commons Attribution Non-Commercial License (http://creativecommons.org/licenses/by$\mathrm{nc} / 3.0 /$ ), which permits unrestricted, non-commercial use, distribution and reproduction in any medium, provided the work is properly cited. 